\title{
PROBLEMS ASSOCIATED WITH THE PRODUCTION AND USE OF VIRAL PESTICIDES
}

\section{S. Y. YOUNG}

Department of Entomology, University of Arkansas, Fayetteville, Arkansas 72701, USA

The development of viral diseases for use as agents in insect pest management (IPM) programs has been an outgrowth of the isolation of highly virulent viruses in natural populations of insect pests. Viral diseases have been isolated from several hundred species of insects (Payne, 1982). Those demonstrated to have the most potential for use in IPM systems are the nuclear polyhedrosis and granulosis viruses of Baculoviridae. Most of these viruses infect the larval stage of Lepidoptera and sawflies of Hymenoptera. They are highly virulent, safe to use, nontoxic to natural enemies, can be produced in quantity in their insect hosts, are stable in the laboratory, easy to apply in conventional pesticide application equipment, and efficacious when used in IPM systems. It is easy to understand why many scientists working in research on biological control have been excited over the potential of these viruses for use in insect pest control. This potential has resulted in a major effort during the past 30 years to develop marketable viral insecticides. Several viral products have been registered for commercial use. However, for the most part, these products have not been well accepted by consumers and have received little use. This can be attributed to an array of problems-encountered in development, use and marketing of viral pesticides.

\section{VIRUSES DEVELOPED AS PESTICIDES}

Viruses that have been evaluated as control agents are numerous. Within lepidopterous and hymenopterous sawfly groups one or more baculoviruses of most major pests of agriculture and forests have been tested in field trials against their hosts. These field trials have usually been small plot trials applied with ground application equipment. Viruses of pests of forests and major agricultural crops have often been applied by airplane as well. Results of field trials have usually shown the viruses to be efficaceous and to have potential for development as pesticides. Yearian \& Young
(1982) listed 31 viruses of agricultural pests that they considered to have shown the most potential up to that time.

Although the list of viruses that has been evaluated in field trials is large, the number that have undergone some degree of commercial development is much smaller. Huber (1986) listed 17 commercial and semicommercial viral preparations of agriculture and forests produced in the United States prior to 1975. These were targeted for only eight pests and many of the preparations were produced by small companies that terminated efforts to register their product. Viral products that have been registered to date in the United States and Canada are listed in the Table. All except one of these products, Elcar, have been developed by the federal forestry services in the United States and Canada for use on forests in the respective country and are not being sold to the public. Quantities of these products have been stockpiled by the respective grovernments to use when pest populations levels warrent application, but since registration little use has been made of these. These agencies at present are less active in pursuing registration of additional viral insecticides.

The only viral product registered by private industry in the United States is Elcar. Elcar was registered in 1976 as a pesticide for Heliothis control on cotton. This was during a period when there was wide spread resistance of Heliothis on cotton to the chemical insecticides in use. As a result there was some interest by producers in using Elcar commercially. It was sold for 2 years and used with limited success in a few selected pest management programs on cotton. After pyrethroid products were registered for use on cotton there was less interest in Elcar and Sandoz, Inc. made the decision that sales were not sufficient to warrent continued marketing of the product and withdrew it from the market. The company maintains large stockpiles of Elcar 
TABLE

Viral products registered for commercial use in the United States and Canada

\begin{tabular}{|c|c|c|c|}
\hline Insect & Crop & $\begin{array}{c}\text { Trade name } \\
\text { (year registered) }\end{array}$ & Manufacturer \\
\hline $\begin{array}{l}\text { Heliothis spp. } \\
\text { Lymantria dispar } \\
\text { Neodiprion sertifer } \\
\text { Orygio pseudotsugato } \\
\text { N. lecontei }\end{array}$ & $\begin{array}{l}\text { cotton } \\
\text { forest } \\
\text { forest } \\
\text { forest } \\
\text { forest }\end{array}$ & $\begin{array}{l}\text { Elcar } \\
\text { Gypchek } \\
\text { Neochek-S } \\
\text { TM-BioControl-1 } \\
\text { Lecontvirus }\end{array}$ & $\begin{array}{l}\text { Sandoz Inc, San Diego, CA, USA } \\
\text { U. S. Forest Service, Hamden, CN } \\
\text { U. S. Forest Service, Hamden, CN } \\
\text { U. S. Forest Service, Corvallis, OR } \\
\text { Canadian Forest Service, Sault Ste. Marie, Ontario }\end{array}$ \\
\hline
\end{tabular}

which have been available for research programs around the world. Sandoz could return the product to the market if it decided that the climate for marketing the product warrants its return. At present, Sandoz is not actively developing any viral products as insecticides. The most serious effort in the United States to register a viral pesticide at present is research by the University of California in cooperation with apple producers to register the codling moth, Laspeyresia pomonella, granulosis virus. Large scale commercial use of a virus pesticide worldwide appears to be limited to the velvetbean caterpillar, Anticarsia gemmatalis, nuclear polyhedrosis virus product developed by EMBRAPA in Londrina, Brazil under the leadership of F. Moscardi (Moscardi, 1983). This product has been routinely utilized in IPM systems to control $A$. gemmatalis in Brazil for the past few years. Virus insecticides registered in other countries and used on a limited basis include a Neodiprion sertifer NPV product in Finland and NPV products of Lymantria dispar, Mamestra brassicae, and Malacosoma naustria and a GV of Hyphantria cunea in the USSR (Huber, 1986).

The viral pesticides as disease producing agents, have certain inherent advantages over conventional insecticides. The viruses have a narrow host range, infecting only a few closely related insect species, and are environmentally safe to use. They do not infect the beneficial insect population so the virus pesticides leave the natural enemy complex intact after their use. Since viruses multiply in their host, there is secondary spread of the disease in the population and persistence of the virus in the area. Additional control will often be obtained in later generations that season or with many agricultural crops and forests in succeding years. If virus insecticides have these important advantages over chemical pesticides and a major effort has been made to develop and use them in agriculture, then why are there not more virus products and why aren't they widely used? The rest of this manuscript will deal with the problems that have been encountered during development of virus pesticides and which drastically limit their commercial use.

Problems Encountered in Viral Insecticide Development and Marketing - Some of the characteristics of virus diseases have hindered their development as pesticides and curtailed the use of these products in IPM systems. There are several major problems associated with the development and public acceptance of virus pesticides. These include the expense and time involved in carrying out tests to satisfy government regulations on safety and efficacy of the product, production and formulation, detailed monitoring of pest population, virus specificity, application technology, efficacy, and marketing. The problems encountered may vary with the virus under development, product use, county in which the product is registered, agency registering the product (public or private sector) and prospective users, but all are important in virus development and use.

Government Regulations for Commercial Virus Pesticide Development - Government regulations for commercial development and use of viral pesticides can vary greatly between countries, but many countries have very stringent regulations for safety and efficacy evaluations. The expense and years involved in bringing a viral insecticide to the market can be an important limiting faster in their development by a governmental or private agency (Batz, 1986).

When development of the Heliothis NPV was begun in the United States in 1961 there were no precedents or guidelines available. Prior to 
full registration of the first commercial virus pesticide, Elcar, very stringent guidelines had been developed and the evolution of these guidelines proved very costly and time consuming. Registration of the Heliothis NPV required millions of dollars and 15 years before becoming commercially available as Elcar. Therefore, virus preparations that before the 1960's had been produced and sold in the United States by small "cottage industries" or producers for use as biological control agents in localized areas was now considered a pesticide. In the United States that meant that regulations and guidelines of the Environmental Protection Agency for insecticide registration now applied. Since the registration of Elcar, requirements for both safety and efficacy tests have changed often and are now less stringent than in the earlier years of virus registration (Bohmfalk, 1986). Registration in the United States remains expensive and time consuming, however, and must be an important consideration before development of a viral product is undertaken. Since patent protection is weak in the case of biological pesticide products in the United States, there is little incentive for private industry to bear the expense of virus pesticide registration. The possibilities for use of virus agents are much better in countries that have less restrictive guidelines or that consider the viruses as natural biological control agents which do not require guidelines (Bohmfalk, 1986).

\section{PRODUCTION AND FORMULATION}

Production - Viruses developed as virus pesticides have and in the near future will continue to be produced in vivo in insect hosts. Small quantities of some NPV can for experimental purposes be developed in vitro, but mass production in cell culture is not economical at present. This means either expensive large insect rearing programs for production or collection of diseased insects from natural populations that have been treated with the virus.

Production of virus products in insects is more complicated and less precise than is production of the conventional chemical pesticides (Ignoffo \& Hink, 1971). Viruses produced in quantity to date have been produced in late instars of the larval stage of Lepidoptera and sawflies. Several of the Lepidoptera can be routinely reared on artificial diets. While this is the best approach to obtain a continuous quantity of virus with a minimum of contamination by other diseases, rearing on artificial diet is often expensive. Some Lepidoptera and the sawflies can not be reared on semisynthetic diet and the virus must be produced in-natural field populations of larvae or larvae reared in the laboratory or greenhouse on plant material. This is often less expensive than rearing on artificial diet. Virus production in natural field populations can be inexpensive in places with a cheap labor source.

There are other major problems with production of viral pesticides in addition to cost (Shapiro, 1982). The insects in which the virus is produced will usually have other diseases as well. A variety of types of disease can often be found in insect populations and these include other viruses. Most of these diseases have low virulence and do not interfere significantly with insect rearing or the quantity of the virus product produced. This possibility must be closely guarded against, however, because an epidemic of another disease could destroy the insect culture and (or) result in a low quality viral preparation. When a virus is produced in insects in which there is an epizootic of another disease, the product produced may be primarily that of the other disease. The presence of other disease agents in the final viral pesticide product can result in failure to fulfill the safety requirements or reduce the effectiveness of the product in the field.

The problem of inconsistant virus production and the presence of extraneous diseases is much more serious when the virus is produced in insect hosts reared on natural host plant material and particularly when produced in insects in natural populations. There are now additives to artificial diet such as antibiotics, fungicides, protozoan inhibitors, etc. that can usually maintain the health of a laboratory reared insect colony and if the virus inoculum is not contaminated a product can be produced with a minimum of contamination. However, in a natural population other diseases with the potential to cause high mortality are often present and much of the mortality observed may be due to the other diseases. When virus production is carried out in a natural insect population, the health of the population, the purity of the virus inoculum used to treat the population and the quality of the virus preparation produced must be monitored closely. Morris et al. (1986) noted that more efficient 
methods of production of microbial agents in general are needed.

Formulation - The basic requirements for formulation of baculoviruses are similar to those for conventional pesticides (Young \& Yearian, 1986). The process must result in a standardized product and preserve insecticidal activity. The final product should have good stability in storage, tank mixing properties and application qualities.

Research on formulation of viruses has been limited and methods used have been primarily those of conventional insecticides. These methods, however, were developed for low molecular weight, fast acting and stable chemical compounds that are primarily contact insecticides. Vir uses are relatively unstable large particulate materials that must be consumed for infection to occur and require days or weeks for death to occur. Therefore, viruses might be better formulated using methodology different from that developed for conventional insecticides. Since virus insecticides must be consumed by the host in order to be effective, host behavior is important and properties of virus formulations may need to differ with the virus, insect host, and crop as well as application method.

The typical virus formulation methods to date have been quite simple such as aqueous suspensions, lyophiled preparations, or acetone precipitation byproducts that were obtained from a filtrate of the macerated cadavers. These simple formulations will often be adequate for application in conventional equipment. They are not stable for long periods at room temperature, however, so must be applied soon after formulation or stored under refrigerated or frozen conditions. This is usually not practical when large quantities of the product are produced or when it must be shipped long distances and stored under a variety of conditions. Such is often the case with pesticides developed by industry. Developing suitable more elaborate formulations has proven difficult. Efforts have concentrated on development of emulsifible concentrates, since the particulate nature of the viruses makes formulation as flowables difficult. The spray-drying formulation process in which the virus is mixed with clay has produced the most stable wettable powder virus formulations. Elcar is produced by this method. This method can not be used for all viruses, however, for the Choristoneura fumiferana NPV lost most activity during the spray-drying process.

The insecticidal activity of a formulation must be standardized for it to be effectively used. If the formulations are not standardized insect control will be erratic, varying from one batch of the product to the next. Standardization is more difficult for virus than chemical pesticides, since virus activity can not be quantified on a weight basis (Dulmage \& Burgerjon, 1977). Most virus formulations have been standardized by determining the concentration of occluded virus using a light microscope and hemacytometer. This may give erroneous results, however, as viral activity per occluded body can change. Even after the virus has been inactivated by conditions such as heat or sunlight the virus remains occluded. A more effective method of standardization is to determine biological activity by bioassay against a susceptible host. This method also has its limitations since it is less precise than desired. Standardization is most successful when both the occluded virus count method and bioassay method are used together.

\section{USE OF VIRAL PESTICIDES}

The development and use of viral pesticides has not progressed as rapidly as might have been anticipated based on their potential. Virus pesticide development has been limited by their inability to compare favorably with chemical pesticides as most are less effective than the best available chemical pesticides. In most instances where virus pesticides are used neither pest population reduction nor crop protection are equal to that of the chemical pesticides in use. Viral pesticides have several characteristics that present problems and limit their effectiveness when used in conventional pest management programs. When virus pesticides have been used for long term control, the comparison with chemical insecticides is more favorable but most virus pesticides in agriculture have not been tested in this way.

Intense pest population monitoring system - The conventional chemical insecticides are typically highly toxic, fast acting and low molecular weight chemicals that kill on contact. Insect pest population monitoring in IPM programs is designed to use this type of insecticide. In contrast, viral pesticides are moderate- 
ly toxic, slow acting particulate-sized stomach poisons. As such, viral pesticides require more intense and expensive pest population monitoring to assure effective use. Producers are obviously reluctant to intensify their pest monitoring system in order to use a viral pesticide if an effective chemical pesticide is available.

Critical timing of viral pesticide application - The characteristics of baculovirus diseases of Lepidoptera and hymenopterous sawflies are such that they attach only the larval stage. Susceptibility to the viruses decreases rapidly as the larvae increase in size so population reduction will usually be much better when applications are timed against the more susceptible young or even newly hatched larvae. In addition, after treatment the disease will take from several days to weeks for symptoms to progress sufficiently for larval feeding and development to cease. Since most crop damage occurs during the final two larval instars (Alam et al., 1987; Harper, 1973), the applications should be timed early so that death will occur prior to these later instars. Furthermore, timing the application against small larvae increases the opportunity for secondary transmission as the virus inoculum released at death of the treated small larvae can spread before other larvae mature. In addition, the behavior of many larval pests is such that newly hatched larvae feed exposed on the plant surface for only a brief period before moving to feed secluded such as within terminals or fruiting structures. Since the virus must be consumed to infect the host, these pests can only be controlled if treated during the period the small larvae feed on the plant surface.

The necessity of timing application against small larvae and anticipation of lower mortality than can be expected from chemical insecticides often requires tha the first virus treatment be applied when the target population numbers are lower than if a chemical pesticide is used. If additional applications are needed, these must often be applied at shorter intervals than chemical insecticides for assurance that larval growth between applications is not excessive. Furthermore, in many instances a virus pesticide will not provide adequate crop protection if target pest populations are high. If this situation develops the user must be prepared to switch from the virus to a chemical pesticide.
Since chemical pesticides provide more consistant mortality than virus insecticides and control is obtained more rapidly, usually within one to two days, the chemicals can be applied with more confidence and evaluated much sooner than virus pesticides. Because of the advantages described above the producer can delay using a chemical pesticide until pest populations are higher and (or) larvae are larger. This may also save applications of insecticide and lower the cost of pest control.

Virus specificity: limited host range - The limited host range of baculoviruses is an important attribute when used in IPM systems since it does not disturb the natural enemy complex. This narrow host range, however, limits the potential use of a virus pesticide to one or at most a few pest species. The potential use is limited further by the frequent occurrance of pest complexes, in which case it is usually desirable to use a chemical pesticide that will control all the pest species in the complex. When pest complexes occur, even if the virus pesticide is used against its target pest, using a chemical to control the remaining pests assures that the natural enemy complex will be destroyed and an important advantage of using the virus is lost.

Furthermore, the narrow host range of viruses is a limitation when viruses are developed for use against sporatic pests. This situation is common and pesticide usage against a particular pest may be widespread one year but very limited or not needed in other years. Under these circumstances effective planning of virus production, distribution and storage is very difficult. Private industry has understandably been reluctant to develop viruses for commercialization unless the host was a major pest which annually required extensive insecticide usage for control.

Limited application technology - Virus pesticides have typically been applied with application equipment developed for conventional chemical insecticides. Whether applied by air or ground equipment, this means that virus pesticides have usually been applied as sprays emulsified in a low volume of water (Young \& Yearian, 1986). This provides adequate coverage for the contact chemical pesticides and allows the applicator to cover a large area using a single tank of spray. Since viruses are large particulate particles that must be consumed to 
be infective, the conventional methods of chemical pesticide application would not appear to be the most suitable. Virus pesticides have an array of potential problems associated with application which do not exist with chemical pesticides.

The viruses infect per os and optimal coverage means the virus must be targeted to feeding sites of the pest. Most conventional equipment, however, is not designed to target droplets, much less alter the coverage pattern as the optimal coverage changes. When viruses are applied to rapidly growing plant surfaces, the coverage changes rapidly after application as the plant growth moves the virus away from the deposit location and the additional surface area dilutes the virus concentration. Although the need for specialized equipment and methodology is recognized there has been little research directed toward developing new application technology for virus pesticides. This reluctance may be influenced by the limited sales potential of any specialized equipment if it was to become available. Potential users of a virus pesticide would be reluctant to purchase specialized application equipment for virus pesticides if effective chemical pesticides which could be used in existing equipment were available.

Virus particles are much larger than the low molecular weight chemical pesticides typically applied and droplet sizes often need to be larger than those used for chemical pesticides. Application equipment, however, is not designed to provide large droplets or to select specific droplet sizes. In addition, virus pesticide tank mixtures are often more complex than those of chemical and further complicate virus pesticide application. The limited effectiveness of viruses applied in conventional application systems may require an array of adjuvants be used. Viruses are rapidly inactivated by the ultraviolet spectrum of sunlight and a variety of sunlight screens may be added to extend coverage on the plant. Spreaders, stickers, and wetting agents may be added to alter the coverage pattern and droplet characterization. Gustatory stimulants can be added to alter behavior of larvae that increase virus consumption. These adjuvants all increase the complexity of tank mixtures, often necessitating the need for larger droplet sizes and spray volume than conventionally used for chemicals.
Marketability of the virus product - The potential users evaluate an insecticide from a practical standpoint and ultimately decide the extent to which the insecticide will be used. The insecticides of choice will typically be the available recommended commercial product that effectively eliminates the insect pest problem with the least inconvenience and expense. The characteristics of virus diseases are such that when compared with chemical pesticides numerous problems are associated with their efficaceous use in IPM systems. They represent to the potential user a new and different kind of pesticide that is not user friendly. The consumer is used to using chemical pesticides that are highly efficacious, easy to use, and provide crop protection that is easily and quickly evaluated. The characteristics of virus diseases are such that from a practical standpoint they usually compare unfavorably with chemical pesticides in these respects and consumers are not confident in their use. There are several practical reasons why the user would choose the chemical over the virus. These reasons to choose the chemical pesticide include (1) More effective reduction of insect population and better crop protection, (2) a less involved pest monitoring system is required, (3) fewer applications may be needed, (4) can be used against pest complexes that include species not susceptible to the virus, (5) can be used against a wider variety of pests in contrast to the virus product which can only be used against one or a few pest species, (6) is much easier to store for lengthy periods, and (7) the producer is more experienced and comfortable in their use. So long as chemical pesticides that offer these advantages are available viral pesticide usage will continue to be very limited.

\section{WHY DEVELOP AND USE VIRAL PESTICIDES}

The advantages that viral insecticides have over chemical insecticides should insure that they have a role in future IPM programs. Viruses have been demonstrated to be environmentally compatable whereas conventional chemical insecticides have a very broad host range and are environmentally harsh. There are also insect pest problems in environmentally sensitive and food crops areas where chemicals can not be used. Efficaceous virus products can offer a satisfactory alternative in these situations. 
In most cropping systems, natural enemies can have a major role in IPM systems in regulating pest population density. Virus pesticides do not directly affect the natural enemy complex, leaving it intact, and further pesticide use may not be needed. Chemical insecticides, however, destroy the beneficial arthropod populations and without them it may be necessary to depend on additional applications of the chemical for insect pest control during remainder of the season.

The conventional chemical pesticides are fast acting with little persistence and as such an application effectively controls the pest for a very short period. Additional control at a later date requires additional applications of the insecticide. Viruses, however, multiply in their insect host after application. Dispersal and secondary transmission of this virus inoculum may provide control over the treated and surrounding areas for future generations and from one year to the next. This characteristic makes virus pesticides particularly attractive for use in control of insect pests of forests and perennial crops of agriculture.

When the insect pest is a foliage feeder or in some other way has feeding behavior such that they typically consume the virus while feeding, the virus effectiveness when properly timed may be comparable to the most efficaceous insecticide. In these instances some of the limitations of the virus product may be overlooked and the virus is more likely to be the product of choice, particularly if it is less expensive.

Insect pests often become resistant to chemical pesticides used against them. In such situations a virus product can rapidly become the most effective pesticide available.

Virus insecticides appear to offer the greatest potential for use in countries in which extensive safety and efficacy evaluations are not required. This would allow small businesses to escape much of the expense of developing and producing a virus pesticide for commercialization and encourage farm groups or other small businesses to produce and market virus products on a small scale for limited markets. Countries in which chemical pesticides are expensive and or limited in availability, and (or) countries in which an inexpensive labor source is available also offer excellent potential for increased virus use. Since virus pesticides are safe they can be applied by hand held equipment in situations where chemical pesticides can not. Application of viruses using hand equipment also allows the selective coverage to feeding sites that is so important in the use of virus pesticides. As a result, control of the target pest is usually improved significantly when hand equipment is used and control is much more likely to be comparable to that of chemical insecticides.

\section{REFERENCES}

ALUM, M. Z.; YEARIAN, W. C.; YOUNG, W. C. \& MUELLER, A. J., 1987. Soybean foliage consumption by Pseudoplusia includens (Walker) (Lepidoptera: Noctuidae) larvae infected with nuclear polyhedrosis virus. J. Entomol Sci., 22:212-223.

BETZ, F. S., 1986. Registration of baculoviruses as pesticides, p. 203. In R. R. Granados \& B. A. Federici, The Biology of Baculoviruses. Vol. II Practical Application for Insect Control. CRC Press, Inc. Boca Raton, FL.

BOHMF ALK, G. T., 1986. Practical factors influencing the utilization of baculoviruses as pesticides, p. 223. In R. R. Granados \& B. A. Federici, The Biology of Baculoviruses. Vol. II Practical Application for Insect Control. CRC Press, Inc. Boca Raton, FL.

HARPER, J. D., 1973. Food consumption by cabbage loopers infected with nuclear polyhedrosis virus. J. Invertebr. Pathol., 21: 191-197.

HUBER, J., 1986. Use of baculoviruses in pest management programs, p. 181 . In R. R. Granados \& B. A. Federici, The Biology of Baculovinuses. Vol. II. Practical Application for Insect Control. CRC Press, Inc., Boca Raton, FL.

IGNOFFO, C. M. S. \& HINK, W. F., 1971. Propaga tion of arthropod pathogens in living systems, p. 541 . In H. D. Burges \& N. W. Hussey, Microbial Control of Insects and Mites. Academic Press, New York, NY.

MOSCARDI, F., 1983. Utilização de Baculovirus anticarsia para o controle da lagarta da soja, Anticarsia gemmatalis. Empresa Brasileira de Pesquisa Agropecuária, Comunicado Técnico, n! 23.

PAYNE, C. C., 1982. Insect viruses as control agents. Parasitology, 84: 35-77.

YEARIAN, W. C. \& YOUNG, S. Y., 1982. Control of insect pests of. agricultural importance by viral insecticides, p. 387. In E. Kurstak, Microbial and Viral Pesticides. Marcel Dekker, Inc., New York.

YOUNG, S. Y. \& YEARIAN, W. C., 1986. Formulation and application of baculoviruses, p. 157. In R. R. Granados \& B. A. Federici, The Baculoviruses. Vol. II. Practical Applications for Insect Control. CRC Press, Inc., Boca Raton, FL. 